\title{
Health Education: Adult Learning in Weight Management Using Weight Tracking Application
}

\author{
Noraini Che $\mathrm{Pa}^{1}$, Sharifah Md Yasin ${ }^{1}$, Muhammad Nizzan Qussyairi Din ${ }^{2}$, \\ Yusmadi Yah Jusoh ${ }^{1}$ \\ ${ }^{1}$ Faculty of Computer Science and Information, UPM; \{norainip; ifah; yusmadi\}@upm.edu.my \\ ${ }^{2}$ Faculty of Computer Science and Information,UPM; nizzan_zzz@yahoo.com \\ https://doi.org/10.37134/jictie.vol6.4.2019
}

\begin{abstract}
The health management is importance to gurantee a human to achievement for a healthy and ability to do their daily task. In view of the health risks of obesity and its prevalance, it is important to provide health education to adults. Weight management knowledge is necessary for any adults in order to control of being overweight or obesity. Obesity increases the risks of developing many types of diseases such as hypertensions, diabetes, heart diseases, gallstones, gout and several types of cancer. The problems faced by some adults is they loved to eat a lot and at the same time they are lacking in doing any exercises. The objectives of this paper are mainly to helps Malaysian citizen to monitor and manage their weight properly through Weight Tracking Application (WTA). This application helps user to check their Body Mass Index (BMI), the ideal calories needed for a daily and the ideal body weight. WTA also provide some exercise recommendations and health tips which helps the user to calculate total calories taken per day and to keep track of their weight changes. WTA is a mobilebased application for iOS and Android that used Hypertext Markup Language (HTML5) and Typescript languages. WTA's users are adults and middle age groups.
\end{abstract}

Keywords: health education, weight tracking application, adult learning, weight management

\section{INTRODUCTION}

Health education is including environmental health, physical health, social health, emotional health, intellectual health, and spiritual health, as well as sexual and reproductive. Health education can be defined as the principle by which individuals and groups of adults learn a method beneficial to the promotion, maintenance, or restoration of health. Health education is combination of planned learning experiences based on theories that provide individuals, groups, and communities the opportunity to acquire knowledge and skills needed to maintain their health. Knowledge of health is important to avoid the health risk and its prevalence. It also shows the need for health education in relation to achieve a healthy body. Weight management is one of knowledge of health which focused on helping user to manage and monitor their body weight. According to Subramaniam, 2016, $30 \%$ of adults are overweight and almost half the population of Malaysia are either overweight or obese. The weight problems are caused by many factors such as the quality of life, the working environment, life style 
and eating habit. "If there is excessive calorie intake, or the calories are not utilized through physical activity, obesity will occur. Therefore, awareness for calorie intake is very important for society to be more careful with their dietary habits." Subramaniam, 2016. There are only a third of Malaysian adults had ever exercised, while only 14 per cent exercised adequately. (New Straits Times, 2017).

Based on Kearsley (2010) adults have great interest for learning subjects that have relevant and give impact to their personal life. Besides that, adults are problem centre learner rather than content-oriented learner. This paper discusses on development of a mobile-based application namely Weight Tracking Application (WTA) that helps citizen in Malaysia to manage their weight properly. The WTA is purposely to educate adults on the important of weight management in daily life to lead a healthy body, create awareness on the criteria that contributes to obesity and to enforce skills on how to manage weight. WTA focuses on rote learning which memorization technique based on repetition. The WTA is able to help user track their weight, provide health tips and basically guide user in managing their weight efficiently. The WTA is able to calculate Body Mass Index (BMI) of the user, keep track of user's weight and provide exercise recommendation and health tips to the user. The WTA is developed based on ionic framework.

This paper contains five part and every parts will be explained in details. Part one explains about the system overview along with its objectives, problem statement, project scope, and expected results of the system. Part two outlines the literature reviews for the existing system and to demonstrate knowledge of the existing body of research in particular topic area. Part three explains about the methodology used in this system development which discuss on system design problems and their solutions. Part four is explains the testing and implementation of the system. Part five describes some concluding remarks for the whole system development.

\section{RELATED WORK}

Adult learning is related to value learning from experience and collaboration of a community and participation in cultures of practice. There are two types of adult learning such as informal and incidental learning. Informal learning is usually intentional but not highly. It's may be taken for granted, tacit, or unconscious. Informal and incidental learning are relevant to many contexts such as the private and public sectors, hospitals, professional associations, religions, families, and communities. Incidental learning is defined as a by-product of some other activity, such as task accomplishment, interpersonal interaction, sensing the organizational culture and trial-and-error experimentation. Informal and incidental learning take place wherever adults have the need, motivation, and opportunity for learning. Informal and incidental learning grows out of everyday encounters and new life experience that offer a challenge, problem to be resolved, or vision of a future. Lohman (2005) defined informal learning as involving those learning activities that employees initiate in the workplace, that involve the expenditure of physical, cognitive or emotional effort, and result in the development of professional knowledge and skills. Informal learning might also involve some form 
of sanctioned learning such as mentoring, coaching, job rotation, job shadowing and special projects or assignments. The informal learning consists of four principles:

1 Context: learning that occurs outside of classroom-based formal educational settings;

2 Cognisance: intentional/incidental learning;

3 Experiential: practice and judgement; and

4 Relationship: learning through mentoring and team working.

In general, obesity is a condition when human Body Mass Index (BMI) is at 30 and above. BMI is a measure of body fat based on the weight in relation to the height and applies to most adult men and women aged 19 and over (Casey et al., 1992). Many adults did not have enough knowledge on how to balance the portion of foods in their meals. More than that, lack of exercise also may be the reason why adults became extremely obese (Chakravarthy \& Booth, 2004). Adults love to eat but their knowledge on the calorie intake is very low. According to The Star Newspaper on 16 June 2014, Malaysia has been rated as the highest among Asian countries for obesity. Consultation on pursuing the treatment on weight loss by dieticians involved with high cost. Besides that, adults nowadays are more focused on their career and they might have no time to do exercise and their lifestyle normally promote eating fast food. For example, physical exercise is the best solution to achieve higher number of energy expenditure due to the burn of calories. Calorie is related to the content of the energy stored in foods or drinks. Adults with unhealthy and inactive lifestyle will likely to have low total energy expenditure as this will surely make them easier to become obese.

There are many factors that make someone to turn into obese such as genes, environment factors such as uncontrolled eating habit, exercises and metabolism, parental fatness, birth weight age of maturation, eating disorder and physiological factor also contribute to the development of obesity (Gazzaniga and Burns, 1993; Parsons et al., 1999, Popkin, 2001). As the technology started to take over the world, it also makes children and adults to move less and less. There are many implications that have to be face by the adults that suffering from obese problem. Spend a lot of time seating and not doing anything can lead to the illness condition and incurable disease (Twisk, 2001). Generally, there is a standard guideline for the men and women about the calories that must be consumed by both genders. Men needed more calorie than women as the tended to use a lot more energy than women. The standard daily calorie needs for men and women are different based on their lifestyle. Professional dietician has provided a solution to reduce the body weight for adults who has an issue with their body size. Doing a physical activity alone cannot guarantee the loss of body weight because the activity only contributes 20 per cent for the body loss while meals that we consumed everyday contributed an astonishing 80 per cent for the weight.

There are various application of weight management developed for iOS and Android users such as MyFitnessPal, Caloriator Calories Calculator, Three Day Diet Plan and Weight Loss Tracker (refer Table 1). MyFitnessPal is a health application that focused on the reducing of body weight based on calories count in which users able to know the amount of daily calories intake based on targeted weight that they want to achieve. The suggestions of exercises with the total calorie burned are also included 
in this mobile application. MyFitnessPal has many features included in this application such as diary section where user can key in the targeted calories goal for a particular day plus exercise that has been done also in that particular day but no feedback module that can give the authority to the user to give an opinion or suggestion in order to improve the overall performance of the application.

Caloriator Calories Calculator is an Android based application that shows amount of calories, carbohydrates, protein and fat in specific products and whole meals that is available on its database. Generally, there are three main modules in this application such as calories calculator, history of entries and amount of calorie needed by a person. The system shows automatically on how much calorie that is required by a person. This can be as an indicator for them to control the intake of calorie. There is no notification module such as email or SMS alert. User cannot make a suggestion or give an opinion to the administrator of the system. More than that, there is no suggestion about the exercise that will assist user in reducing body weight.

Three Day Diet Plan is an application that gives tips to the user about how to lose weight only in three days. There is a fix suggestion about foods and beverages that must be consume by the user in order to create a unique metabolic reaction and boost fat burning only in three days. There is no calorie value stated for each food and drink that has been suggested. Besides that, the choices of foods and drinks are very limited which only about thirty types of foods and drinks available. Feedback sections are not available in this application so it is hard for user to make any complain or give opinions regarding the application. This application provides the guideline about the foods and beverages that must be consume according to the standard of dietician and suggestions about the exercises also been included in this application.

Weight Loss Tracker is developed by aktiWir GmbH. It is a mobile-based application which is a free application but offers in application purchases. The app provides user with a detailed body weight diary including graphical statistics on user's body weight improvements. When updating the user's body weight, the application will track and comment on their achievements and continuously encourage the user to improve. Dashboard Page of Weight Loss Tracker applications have some functionalities provided in the application but based on the comparison, and mostly the application does not provide exercise recommendation for the users who have weight problems. It means that the user has no idea what are the best and simple exercises to do in dealing with their problems. Besides, most of application did not provide the user ideal daily calorie intake features which mean that the user does not know the ideal calorie intake for them. Apart from that, not all application provide calorie counting features thus this makes it harder for the user to follow the ideal calories provided. This will then led to the user to over eating or eat fewer calories than the ideal calories intake provided. 
Table 1: Comparison Between Weight Management Application in iOS or Android

\begin{tabular}{lcccc}
\hline \multicolumn{1}{c}{ Specification } & $\begin{array}{c}\text { MyfitnessPal } \\
\text { (iOS and Android }\end{array}$ & $\begin{array}{c}\text { Three Day } \\
\text { Diet Plan } \\
\text { (ioS) }\end{array}$ & $\begin{array}{c}\text { Caloriator } \\
\text { Calories } \\
\text { Calculator (iOS and } \\
\text { Android }\end{array}$ & $\begin{array}{c}\text { Weight Loss } \\
\text { Tracker }\end{array}$ \\
\hline Login Module & Yes & No & Yes & Yes \\
Registration Module & Yes & No & Yes & Yes \\
Portable & Yes & Yes & Yes & Yes \\
Create Statistic & Yes & No & No & No \\
Selection Of Food Module & Yes & Yes & Yes & Yes \\
Suggestion of Exercise Module & Yes & No & No & No \\
\hline
\end{tabular}

\section{RESEARCH METHODOLOGY}

In developing Weight Tracking Application, several phases included such as planning, designing, analysing, and construction. The methodology used in this research is Rapid Application Development (RAD) which helps to build a complete application in short period of time and an earlier detection of error has encourage the user of the system to give a feedback.

\section{THE DEVELOPMENT OF WEIGHT TRACKING APPLICATION(WTA)}

In considering the four principles of adult learning as mentioned in related work, the development of WTA considers the interests for learning subjects that are relevant. WTA is developed for adult users in iOS and Android application. Besides that, WTA is catering for problem centred learning rather than content-oriented learning.

\section{Analysis and Planning}

In planning phase, the problem statement, scope and objective has been highlighted to give early exposure regarding on the criteria that is required to construct this system. Analysis phase is carried out to evaluate and compare the existing system to ensure that the problems that have been collected. In addition, the comparison between each existing system has been reviewed precisely so that the proposed system can cover the limitations of the existing system. The process of data collection about user requirement is also important to ensure that it is suitable for use in the process of developing the system. Besides that, the principle of informal learning as mentioned in related work such as context, cognisance, experiential and relationship also considered in this phase. Information about the scenario of obesity in adults of Malaysia has also being classified. The scope of the project of the system has been explained to give the clear and detailed explanation about the features that has been added to the system. The proposed system will give a guideline to the targeted user about information and nutrients of local foods. WTA focused on local foods and drinks of Malaysia. Besides that, it's promoted the 
guideline about various forms of exercises that can be practice by the user to promote the weight loss as a solution for the obesity adults who wished to change their eating habit and achieved an ideal weight. This system is capable to be understood by adults as it is user friendly. Design of the system are based on Table 2, there are six functionalities of the Weight Tracking Application identified such as Input Meal, Provide Recommendation, Generate Statistics and Manage Profile. (refer in Table 2).

Table 2: Use Case Identifier

\begin{tabular}{|c|c|c|}
\hline IDENTIFIER & USE CASE & DESCRIPTION \\
\hline SRS_REQ_1 & $\begin{array}{l}\text { SRS_UC_1 } \\
\text { Create Account }\end{array}$ & New user needs to create an account in order to log in into the application \\
\hline SRS_REQ_2 & $\begin{array}{l}\text { SRS_UC_2 } \\
\text { Login }\end{array}$ & User can login into the application \\
\hline SRS_REQ_3 & $\begin{array}{l}\text { SRS_UC_3 } \\
\text { Input Meal }\end{array}$ & $\begin{array}{l}\text { User can select meal and calculate total calories value for the selected } \\
\text { meals }\end{array}$ \\
\hline SRS_REQ_4 & $\begin{array}{l}\text { SRS_UC_4 } \\
\text { Provide Recommendation }\end{array}$ & User can view recommendation and health tips. \\
\hline SRS_REQ_5 & $\begin{array}{l}\text { SRS_REQ_5 } \\
\text { Create Statistics }\end{array}$ & User can record and update their weight changes. \\
\hline SRS_REQ_6 & $\begin{array}{l}\text { SRS_REQ_6 } \\
\text { Manage Profile }\end{array}$ & User can view and update their profile information. \\
\hline
\end{tabular}

\section{System Implementation and Testing}

System implementation is a process that converts the requirements and design into code using selected programming language. For Weight Tracking Application, it is mobile-based application that are build using Hypertext Mark-up Language 5 (HTML5), Typescript and JQuery. WTA involved a testing process in order to assured the completeness and integrated of the system. The purpose of this test is to evaluate the system's compliance with the specified requirements. The objectives to proceed with system testing are:

1 To validate the functionality of the system so that it will follow the requirement.

2 To ensure the system is ready to be delivered to the end user.

3 To ensure there is no error presents in the system.

The errors that can be detected such as incorrect functions in the application, errors in performance, interface and database, input data error and missing text field and difficulty in understanding the system

\section{WEIGHT TRACKING APPLICATION}

WTA is a weight management application that helps user to monitor their body weight. It also provides user's ideal body weight which act as a guide for the user. There are three different formulas for calculating user's ideal weight which are used by G. J. Hamwi, J. D. Robinson and D. R. Miller. The 
Total Daily Energy Expenditure (TDEE) is an estimation of how many calories burn per day when exercise is taken into account. It is calculated by first figuring out user Basal Metabolic Rate, then multiplying that value by an activity multiplier. Below are the steps needed to calculate TDEE. For different gender, TDEE has slight different in formula of calculating. WTA is developed for the user to manage their weight properly. WTA focuses on four learning outcomes as follows:

1 User able to check their BMI status, their ideal calories needs to be taken daily and their ideal body weight

2 User aware on the exercise recommendations and health tips

3 User able to calculate total calories taken by the user per day

4 User able to keep track of their weight changes daily

Based on adult learning, the elements of context, cognisance and experiential learning are used in WTA. The context is related to subject of study that is weight management. The cognisance is intentional learning in weight management for adult. The experiential learning occurs when the user input data, then WTA generate output and recommendation of health tips. Functionalities provided by WTA support the elements of cognisance and experiential learning. WTA interfaces provide user BMI score, user ideal calories and user ideal body weight. There are 3 different ideal weights provided to the user using three different calculations which are based on G. J. Hamwi Formula, J. D. Robinson Formula, and D. R. Miller Formula.

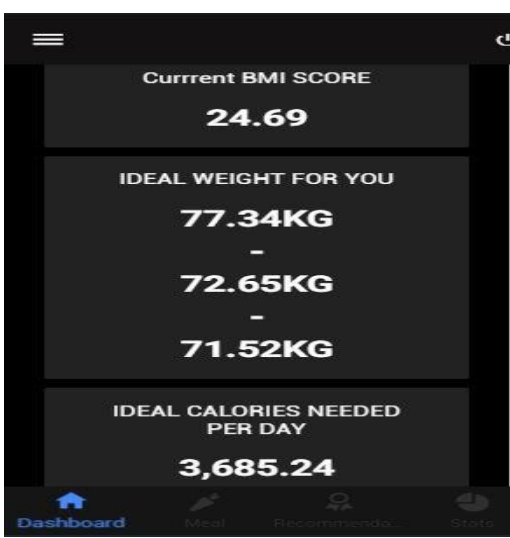

Figure 1: Dashboard Interface

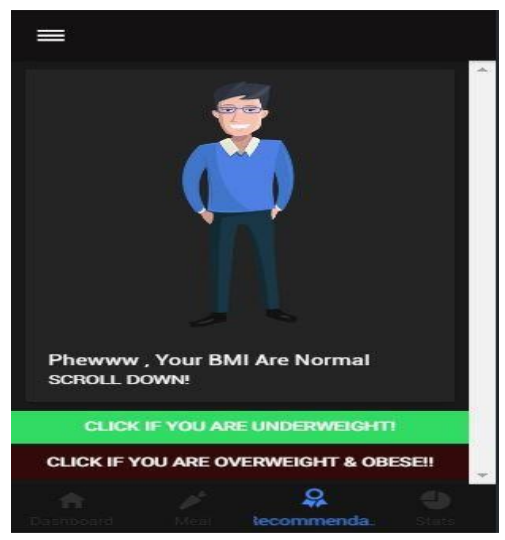

Figure 2: Recommendation Module Interface

Figure 1 shows the Dashboard Interface for WTA. User has to select the gender and the meal time before making a meal selection. Gender available is male and female while meal time available is breakfast, lunch and dinner. The calorie suggested for male are $500 \mathrm{cal}$ while women are $400 \mathrm{cal}$. When user chooses meal that exceeds the limit of the calorie range, there will be pop-up message that indicate the remainder and user cannot proceed to the next stage of meal time. User can see name of meal that they have selected according to the meal time. The food will be listed in the bullet form. Then a graph chart showed the intake of calorie by user. Figure 2 shows the Recommendation Module which 
provides user BMI status, exercise recommendations and health tips. In the statistic module, user can update their weight and fill the required information and able to keep track of their weight changes in the form of line graph.

\section{CONCLUSION}

In adult learning, elements of context, cognisance and experiential learning are used in learning weight management. These elements supported with the functionalities provided by WTA for Malaysian adults. WTA can be used for iOS and Android users. Adults are expected to gain the four learning outcomes: ability to check BMI status, ideal daily calories and ideal body weight; capable to calculate total daily calories; ability to keep tracking daily weight changes; and gain awareness on the exercise recommendations and health tips. WTA can aid in educating user how to manage their body weight. Adults learn how to calculate BMI, to manage and calculate daily total calorie intake while keeping track on weight changes in achieving ideal weight. Additionally, adults will learn how to plan and select diets suitable for them. The exercise recommendation and health tips provided by WTA will create awareness to adult on their health. This application educates the Malaysian adults to manage their weight properly. This paper has not covered on the validation phase but it focuses on developing WTA. For future work, it will report validation result that involve with the target users. In general, this application will educate adults about health awareness and weight management in order to live in better health condition due to cater the obesity problems that can be linked with dangerous diseases.

\section{ACKNOWLEDGEMENT}

The authors acknowledge the financial supported by the Fundamental Research Grant under grant number FRGS/1/2016/ICT01/UPM/02/3 (Project code: 08-01-16-1851FR) received from the Ministry of Education, Malaysia via Universiti Putra Malaysia (UPM).

\section{REFERENCES}

Bahagian Pemakanan Kesihatan Malaysia (2018). Panduan Nilai Kalori Makanan Dalam Makanan.

Buragga, K., \& Zaman, N. (2013). Software development techniques for constructive information systems design (1st ed.). Hershey, PA: Information Science Reference

Casey, V. A., Dwyer, J. T., Coleman, K. A., \& Valadian, I. (1992). Body mass index from childhood to middle age: a 50-y follow-up. The American Journal of Clinical Nutrition, 56(1), 14-18.

Chakravarthy, M.V. and Booth, F.W. (2004). Eating, exercise, and "thrifty" genotypes: connecting the dots toward an evolutionary understanding of modern chronic diseases. Journal of Applied Physiology, 96: 3-10.

Chakravarthy, M.V. and Booth, F.W. (2004). Eating, exercise, and "thrifty" genotypes: connecting the dots toward an evolutionary understanding of modern chronic diseases. Journal of Applied Physiology, 96: 3-10.

Gazzaniga, J. M., \& Burns, T. L. (1993). Relationship between diet composition and body fatness, with adjustment for resting energy expenditure and physical activity, in preadolescent children. The American Journal of Clinical Nutrition, 58(1), 21-28.

Manuti, A. Pastore, S., Scardigno, A. F., Giancaspro, M. L. and Morciano, D. Formal and informal learning in the workplace: a research review. International Journal of Training and Development 19:1

Marsick, V. J and Watkins, K. E. (2001). Informal and Incidental Learning. John Wiley \& Sons, Inc. 89. 
Health Education: Adult Learning in Weight Management Using Weight Tracking Application

Received Date: 3 January 2019; Accepted Date: 02 April 2019

Parsons, T. J., Power, C., Logan, S., \& Summerbelt, C. D. (1999). Childhood predictors of adult obesity: a systematic review. International Journal of Obesity, 23.

Popkin, B.M. (2001). Nutrition in Transition: the changing global nutrition challenge. Asia Pacific Journal of Clinical Nutrition, 101: S13-18.

Thestar.com.my,. (2014). Malaysia's obesity rate highest in Asia - Nation | The Star Online. Retrieved 13 December 2015, from http://www.thestar.com.my/News/Nation/2014/06/16/obesity-malaysia-highest-in-asia-says-pm-science-advisor/ 